\title{
Self-reported sleep disturbances in renal transplant recipients
}

\author{
Hanna Burkhalter ${ }^{1,5}$, Daniel P Brunner ${ }^{2}$, Anna Wirz-Justice ${ }^{3}$, Christian Cajochen ${ }^{3}$, Terri E Weaver ${ }^{4}$, Jürg Steiger ${ }^{5}$, \\ Thomas Fehr ${ }^{6}$, Reto M Venzin ${ }^{7}$ and Sabina De Geest ${ }^{1,8^{*}}$
}

\begin{abstract}
Background: Poor sleep quality (SQ) and daytime sleepiness (DS) are common in renal transplant (RTx) recipients; however, related data are rare. This study describes the prevalence and frequency of self-reported sleep disturbances in RTx recipients.

Methods: This cross-sectional study included 249 RTx recipients transplanted at three Swiss transplant centers. All had reported poor SQ and / or DS in a previous study. With the Survey of Sleep (SOS) self-report questionnaire, we screened for sleep and health habits, sleep history, main sleep problems and sleep-related disturbances. To determine a basis for preliminary sleep diagnoses according to the International Classification of Sleep Disorders (ICSD), 164 subjects were interviewed (48 in person, 116 via telephone and 85 refused). Descriptive statistics were used to analyze the data and to determine the frequencies and prevalences of specific sleep disorders.

Results: The sample had a mean age of $59.1 \pm 11.6$ years (60.2\% male); mean time since Tx was $11.1 \pm 7.0$ years. The most frequent sleep problem was difficulty staying asleep (49.4\%), followed by problems falling asleep (32.1\%). The most prevalent sleep disturbance was the need to urinate (62.9\%), and 27\% reported reduced daytime functionality. Interview data showed that most suffered from the first ICSD category: insomnias.

Conclusion: Though often disregarded in RTx recipients, sleep is an essential factor of wellbeing. Our findings show high prevalences and incidences of insomnias, with negative impacts on daytime functionality. This indicates a need for further research on the clinical consequences of sleep disturbances and the benefits of insomnia treatment in RTx recipients.
\end{abstract}

Keywords: Renal transplantation, Sleep disturbances, Sleep quality, Daytime sleepiness

\section{Background}

Poor sleep quality is common among renal transplant (RTx) recipients, with a prevalence ranging from $30 \%$ to $62 \%[1-4]$ as measured using the Pittsburgh Sleep Quality Index (PSQI). Subjective sleep quality (SQ) is an evaluation of sleep by the affected individual [5], covering elements such as total sleep time, sleep onset latency, total waking time, sleep efficiency and disruptive events. Daytime sleepiness (DS) involves difficulty maintaining a desired level of wakefulness, i.e., the feeling of drowsiness with a tendency to doze [6].

\footnotetext{
* Correspondence: sabina.degeest@unibas.ch

'Institute of Nursing Science, University of Basel, Basel, Switzerland

${ }^{8} \mathrm{Center}$ for Health Services and Nursing Research, KU Leuven, Belgium

Full list of author information is available at the end of the article
}

One cross-sectional study using the PSQI in a Swiss transplant center reported a poor SQ prevalence of $47.4 \%$ [7]. As measured using the Epworth Sleepiness Scale (ESS), [8] data from three Swiss transplant centers showed a prevalence of $52 \%$ for poor SQ [8] and $50.9 \%$ for daytime sleepiness (DS). Most cross-sectional studies suggest that poor SQ is higher pre-RTx $(49 \%-78 \%[3,9,10])$ than postRTx (30\%-52\% [1,11]). Similarly, insomnia (difficulty falling asleep, staying asleep, waking up before the desired time and being left tired during the day) in RTx candidates [12] has a prevalence of $15 \%$ in patients on maintenance dialysis, compared to $8 \%$ post-RTx [13]. Post-RTx SQ remains constant [14]. Supporting these findings, Sabbatini et al. (2005) showed that sleep significantly improved from pre- (PSQI mean: $8.52 \pm 3.81, \mathrm{P}<0.001$ ) to post-RTx (PSQI mean: $6.46 \pm 3.71, \mathrm{P}<0.001$ ), although it remained

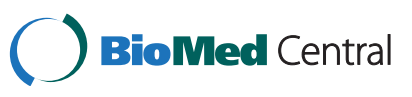


higher than in control subjects $(3.54 \pm 1.61, \mathrm{P}<0.0001)$ [3]. Finally, poor SQ has been linked to pre-RTx impaired health status $[14,15]$, with post-RTx health status improving alongside SQ [13,16].

The most frequent sleep disorders among hemodialysis patients are conditioned insomnia (unconscious association of bedtime with negative feelings), obstructive or central sleep apnea (repeated cessation of breathing during sleep), restless leg syndrome (an irresistible urge to move the legs) and periodic limb movement disorder (involuntarily limb movements) [17]. In patients with end-stage renal disease, several uremic and non-uremic factors are thought to contribute to the pathogenesis of sleep disorders [17]. Sleep apnea appears to be related to displacement of fluids which destabilize the control of breathing and narrow the upper airway [18]. Restless leg syndrome and periodic limb movement disorders are correlated with anemia, iron deficiency, and peripheral and central nervous system abnormalities. Therefore, most such disorders improve post-RTx [18]. Excessive daytime sleepiness occurs in approximately $50 \%$ of patients with endstage renal disease [19], the etiology of which appears related to both uremia and sleep fragmentation [19].

Self-report screening questionnaires to assess sleep problems are an efficient preliminary step in a sleep diagnostic process before the first assessment interview. However, screening survey data analyses cannot do more than generally categorize sleep complaints. A detailed diagnosis of a sleep disorder requires sleep experts and specific diagnostic tools. In sleep medicine, diagnosis follows the International Classification of Sleep Disorders (ICSD), which groups disorders into eight categories: (1) Insomnias; (2) Sleep Related Breathing Disorders; (3) Hypersomnias (excessive daytime sleepiness); (4) Circadian Rhythm Sleep Disorders; (5) Parasomnias (strange movements, behaviors, emotions, perceptions, and dreams during sleep); (6) Sleep Related Movement Disorders; (7) Isolated Symptoms, Apparent Normal Variants and Unresolved Issues; and (8) Other Sleep Disorders [20]. ICSD diagnosis guidelines require a clinical assessment interview and may specify diagnostic tools (e.g., polysomnography [21] or biophysiological measurement [22]) to differentiate sleep disorders from others with similar symptoms.

In summary, sleep quality normally improves after RTx; [3] however, a high proportion of the current study's RTx recipients were still suffering from sleep disorders several years post-Tx [8]. Prior to this study, no self-reported data existed on sleep disturbances among (post-Tx) RTx recipients. Therefore, the aims of this study were:

1) to describe the frequency of self-reported sleep disturbances in RTx recipients screened with the Survey of Sleep (SOS); and
2) based on structured sleep assessment interviews, to measure the prevalence of sleep disorders in RTx recipients.

\section{Methods}

\section{Design, setting and sample}

This study used a sequential cross-sectional multicenter design with a sample of 249 adult home-dwelling RTx patients, all of whom were participating in a larger study on sleep and daytime sleepiness. The inclusion criteria were: (1) RTx took place at one of the three participating Swiss transplant centers, (2) a functioning renal graft at least 6 months post-Tx, (3) the ability to understand and read German, (4) 18 years of age or older, and (5) participation in the preceding study with poor SQ (PSQI $>5$ [23]) and/or DS (ESS > 6 for increased DS [24]) scores. Candidates were excluded if they were undergoing dialysis or had not signed the written informed consent form.

The stage sampling approach used was based on candidates' PSQI and ESS scores, both of which were assessed as a part of the larger study [8]. The PSQI is a self-rated questionnaire consisting of 19 items, assessing a wide variety of factors related to sleep quality over a 1 month period, including estimates of sleep duration and latency, and of the frequency and severity of specific sleep-related problems. These 19 items are grouped into seven component scores, each weighted equally on a 0 3 scale. The seven component scores are then summed to yield a global PSQI score, which has a range of 0-21; higher scores indicate worse sleep quality. A cut-off of $>5$ points is used to classify patients as having poor sleep quality [23]. The ESS is a validated eight-item questionnaire to measure a subject's expectation of dozing (falling into a light sleep) in eight hypothetical situations. Dozing probability ratings range from 0 (no probability) to 3 (high probability). An ESS total score $\geq 6$ indicates DS [25]. A score $\geq 10$ indicates that a person tends to become very sleepy and should seek medical advice [25]. All 249 provided self-reported Survey of Sleep (SOS) data; a subsample $(\mathrm{n}=164)$ additionally participated in a sleep assessment interview (83 declined participation).

\section{Variables and measurements}

Age (in years), gender, years since transplantation, body mass index $\left(\mathrm{kg} / \mathrm{m}^{2}\right)$, creatinine $(\mu \mathrm{mol} / \mathrm{l})$, hemoglobin $(\mathrm{g} / \mathrm{l})$ and drugs (including sleep drugs) were retrieved from the participants' hospital medical charts. Comorbidity data were also extracted from patients' charts and categorized using the Charlson comorbidity index [26], which assigns various weights to specific conditions. Each of the 19 noted conditions was assigned a score of $1,2,3$, or 6 , depending on the associated mortality risk. For each patient the scores were summed to provide his or her overall comorbidity score [26]. Sleep quality and daytime sleepiness 
was extracted from the preceding study and categorized in three groups: 1) $\mathrm{PSQI} \leq 5$ (good SQ) \& $\mathrm{ESS} \geq 6$ (DS); 2) $\mathrm{PSQI}>5$ (poor SQ) \& $\mathrm{ESS}<6$ (no DS); 3 ) $\mathrm{PSQI}>5$ (poor $S Q) \&$ ESS $\geq 6$ (DS).

\section{Survey of sleep (SOS)}

The self-reported Survey of Sleep (SOS) questionnaire was developed at the University of Pittsburgh and translated into German by the second author. It is often used to report sleep symptoms in insomnia patients, [22] and studies often employ it as a preparatory step before carrying out sleep assessment interviews $[27,28]$. The questionnaire consists of 7 sections: (1) sleep overview (existence of problem(s) (yes/no), general sleep problem (main complaint); duration (less/more than 1 year), course (getting worse, same, better, irregular), and frequency of the sleep problem (once/month, several times/week, nightly)); (2) sleep habits (including bedtime, get-up time and sleep latency in hours and minutes, whether the subject sleeps better in another location (yes/no), regularity of bedtimes (yes/no); (3) sleep disturbances (sleep-related symptoms and a list of 45 potential disturbances); (4) daytime function (typical feelings on getting up (energetic, optimistic, refreshed, low energy, irritable, depressed, confused, anxious); nap behavior (intentional or unintentional naps, dreaming during the naps (yes/no), feeling more alert after the nap (yes/no), daytime function (sleepiness (not at all, slightly, moderately, extremely), accidents because of sleepiness (yes/no), fatigue (not at all, slightly, moderate, extremely), having to close eyes during the day to relax (yes/no), impaired daytime function (yes/no), most functional period of the day (early or late morning, afternoon or evening; night; no particular time), (5) health habits (use of sleeping drugs (Yes/No), caffeine (amount in cups), nicotine (number of cigarettes per day), alcohol use (glass unit per day), (6) sleep history (select the main complaint); and (7) medical history (diagnoses, drugs) [29].

The estimated time necessary to complete the SOS is 30 minutes. There is no sum scoring of the items and as of the time of writing no validity or reliability measures are available for it, as it was developed as a guide for an sleep assessment interview and not as a diagnostic tool [22]. The complete Survey of Sleep (SOS) questionnaire is available on request from the second author.

\section{Sleep assessment interview}

Data from the SOS were used to prepare and structure the sleep assessment interview. All responses indicating possible sleep disturbances were addressed and elaborated on in the interview, which was structured to follow the 7 SOS sections, and lasted approximately one hour. The information generated by the interview helped to exclude some sleep disorders; however, as no follow-up visits took place and no further sleep diagnostic measurements or tools were used, the given diagnoses according to the ICSD criteria [20] should be regarded as preliminary.

The interviewer (first author) was trained to perform sleep assessment interviews by a certified sleep specialist and somnologist at the Hirslanden Sleep Disorders Center in Zollikon, Switzerland. This training included an overview of sleep disorders and of the techniques used to diagnose them. The second author checked a random sample of the completed interview transcripts and evaluated the comprehensive justification (to provide inter-rater reliability) of the preliminary sleep diagnoses. He also provided back-up assistance in view of resolving difficulties in assessment or categorization of sleep disorders.

\section{Data collection}

Patients were informed at the start of the research project [8] that they might be invited for a further screening and assessment if their initial data indicated poor SQ and/or DS (see flowchart, Figure 1). Each such patient received a package containing an information letter, informed consent documents, a pre-stamped return envelope and the Survey of Sleep questionnaire (SOS). Candidates were included in the study if they signed the informed consent form, completed the SOS and returned the documents.

Data collection started in June 2011 at the first transplant center and ended in June 2012 at the third. Patients who had not responded within 2 months of the document mailings were contacted by phone to ask whether they had received the material and would still be willing to complete the questionnaire. Each eligible patient $(\mathrm{N}=249)$ was contacted to set up a sleep assessment meeting, which could be conducted either in person or via telephone. Only 48 agreed to in-person interviews; 116 agreed to a phone interview. After 10 unsuccessful call attempts, the patients were categorized as unreachable or it was noted that they had declined to participate $(n=85)$. According to each participant's wishes, the first author either met him/her at a predetermined place or called at the predetermined time.

The study was approved by the ethics committees of all three transplant centers (Ethikkommission beider Basel; Kantonale Ethikkommision Bern; Kantonale Ethikkommision Zürich). Data were anonymized following the interview and stored in an electronic databank. Participants given preliminary diagnoses were encouraged to consult their nephrologists regarding their sleep problems. Any patient who wished also received a list of certified sleep disorder centers in Switzerland for further examination and treatment.

\section{Statistical analysis}

Descriptive statistics (means, standard deviations (SD), medians, quartiles, and frequencies) were used as appropriate, based on measurement levels and variable distributions. 


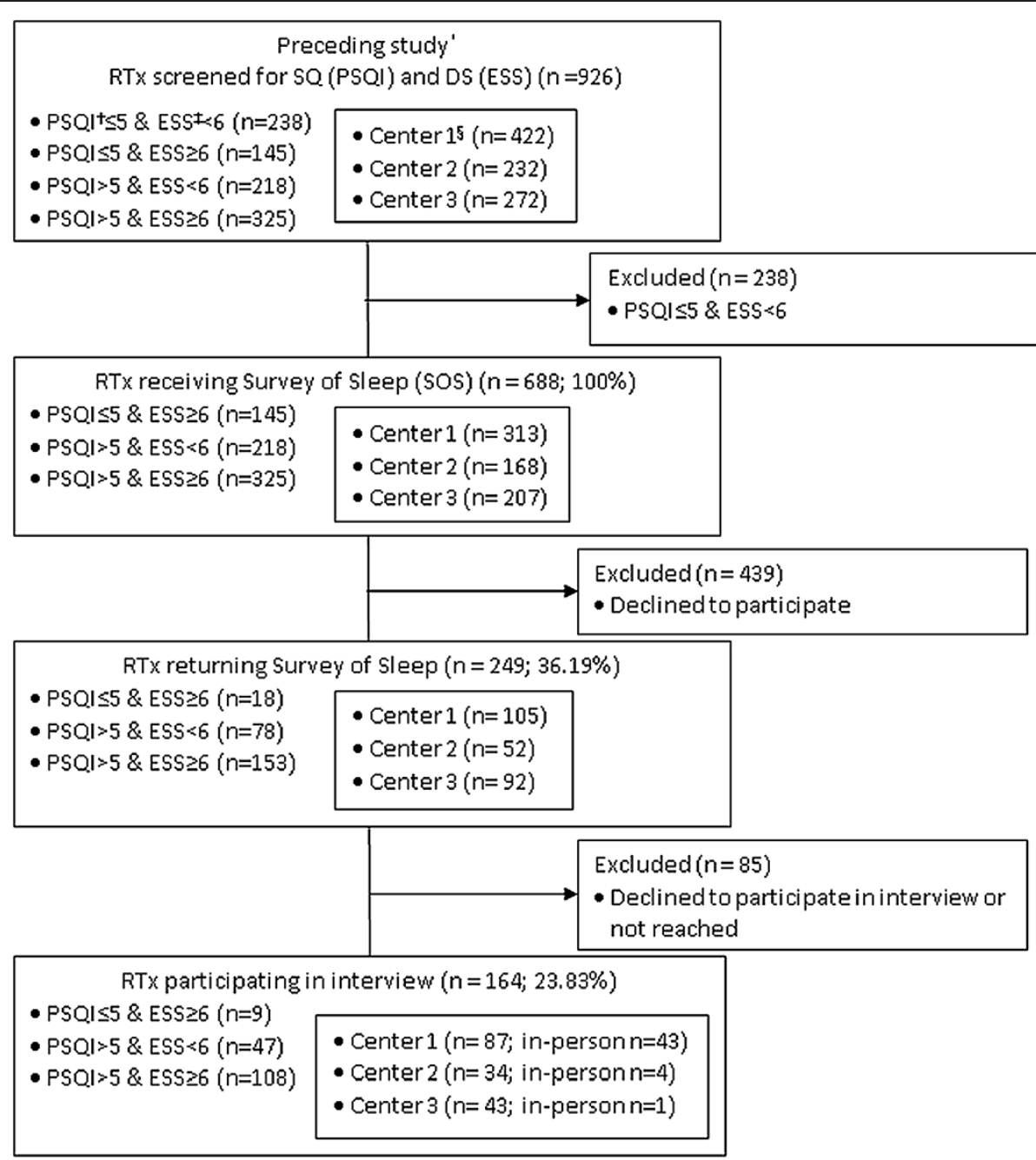

Figure 1 Flowchart of the sample.

Likewise, comparisons between respondents and nonrespondents were performed via t-test, Goodman and Kruskal's gamma test, or Mann-Whitney U test. Missing values were left blank and analysis was performed on the values given. SPSS Statistics software (Version 19.0.0, IBM Corporation, Somers NY) was used for statistical analysis, with all critical probability levels set to $5 \%$.

\section{Results}

Of $688 \mathrm{RTx}$ recipients invited to participate in this study, 249 (36.2\%) agreed. Of 145 RTx with PSQI $\leq 5$ (good SQ) \& ESS $\geq 6$ (excessive DS), 18 (12.41\%) participated; of 218 with PSQI $>5$ \& ESS $<6,78$ (35.78\%) participated; and of 325 with PSQI $>5$ \& ESS $\geq 6,153$ (47.08\%) participated (Figure 1). Participants did not differ significantly from non-participants regarding age, gender, years since transplantation, comorbidities or daytime sleepiness. However, poor SQ (PSQI score $>5$ ) was significantly more prevalent among participants (Gamma: 479, df: $48 ; \mathrm{p}=0.0001)$. Of the 249 participants who filled in the SOS questionnaire, $164(65.8 \%)$ participated in the subsequent sleep interview (Figure 1). The patients with PSQI $>5$ (poor SQ) \& ESS $\geq 6$ (excessive DS) scores also had the highest participation rate in the assessment interview (65.8\%). Most in-person sleep assessment interviews $(n=43)$ were performed with patients from center 1 in connection with a nephrology follow-up visit, where the first author has a clinical position. Participation in the sleep interview was much lower for patients in centers 2 and 3, as each interview required 1-4 hours of travel either for the patient or for the interviewer, and no possibilities existed to connect the interviews with nephrology follow-ups.

The participants had a mean age of $59.1 \pm 11.6 y ; 60.2 \%$ were male and the mean time since RTx was $11.1 \pm$ 7.0 years (Table 1 ). Immunosuppressive therapy, sleep drugs and co-medications, health habits and sleep history data are listed in Table 1. Sleep drug frequency, as 
Table 1 Characteristics of the sample [chart review and SOS part 5 (health habits), 6 (past sleep history) \& 7 (medical history)]

\begin{tabular}{|c|c|c|}
\hline All $(\mathrm{N}=249)$ & Frequency & Percentage \\
\hline \multirow[t]{2}{*}{ Male } & 151 & 60.2 \\
\hline & Mean & Std \\
\hline Age in years & 59.6 & 12.1 \\
\hline Years since RTx & 11.1 & 7.0 \\
\hline Body Mass Index $\left(\mathrm{kg} / \mathrm{m}^{2}\right)$ & 25.9 & 5.2 \\
\hline Creatinine $(\mu \mathrm{mol} / \mathrm{l})$ & 125.0 & 81.6 \\
\hline \multirow[t]{2}{*}{ Haemoglobin (g/l) } & 127.6 & 16.5 \\
\hline & Median & $(25 Q-75 Q)$ \\
\hline Charlson Comorbidities Index & 1 & $0-2$ \\
\hline Immunosuppressive drugs & Frequency & Percentage \\
\hline Cyclosporin & 103 & 41.4 \\
\hline Tacrolimus & 93 & 37.3 \\
\hline Sirolimus, Everolimus & 23 & 9.2 \\
\hline Mycophenolat & 152 & 61.0 \\
\hline Azathioprine & 38 & 15.3 \\
\hline Corticosteroids & 78 & 31.3 \\
\hline \multicolumn{3}{|l|}{ Co-medication chart review } \\
\hline Statin & 97 & 39.0 \\
\hline ACE inhibitor & 61 & 24.5 \\
\hline Angiotensin receptor blocker & 68 & 27.3 \\
\hline Calcium channel blocker & 43 & 17.3 \\
\hline Beta blocker & 92 & 36.9 \\
\hline Anticoagulants & 58 & 23.3 \\
\hline Antidepressants & 14 & 5.6 \\
\hline Diuretics & 42 & 16.9 \\
\hline Sleep drugs & 9 & 3.6 \\
\hline Self-reported sleep drug use & 82 & 32.9 \\
\hline Caffeine use ( $>2$ cups/d) & 132 & 62.3 \\
\hline Nicotine use & 31 & 12.4 \\
\hline Alcohol use (>1 glass/day) & 64 & 25.8 \\
\hline \multicolumn{3}{|l|}{ Sleep history in childhood } \\
\hline Insomnia & 24 & 9.6 \\
\hline Sleepwalking & 16 & 6.4 \\
\hline Bed-wetting & 24 & 9.6 \\
\hline Talking in your sleep & 29 & 11.6 \\
\hline Nightmares & 21 & 8.4 \\
\hline Night terrors (screaming in the middle of the night and being difficult to awaken) & 6 & 2.4 \\
\hline Head-banging or body rocking & 8 & 3.2 \\
\hline Seizures during sleep, while falling asleep, or while waking up & 5 & 2.0 \\
\hline Daytime sleepiness & 12 & 4.8 \\
\hline Snoring & 12 & 4.8 \\
\hline Breathing difficulties & 5 & 2.0 \\
\hline
\end{tabular}


noted in the nephrology charts, was $1.6 \%$ for benzodiazepines and $2.0 \%$ for other sleep drugs. The prevalence of self-reported sleep medication in the SOS was $32.9 \%$.

\section{Prevalence and percentage of sleep problems and sleep habits [SOS part $1 \& 2$ ]}

The most frequent sleep problem was difficulty staying asleep (49.4\%), followed by difficulty falling asleep (32.1\%) (Table 2). Most RTx recipients (61.4\%) had experienced their sleep problems longer than 2 years without change (45\%) and for $43.8 \%$ the problems occurred every night.

Prevalence and percentage of sleep symptoms [SOS part 3] Of 45 sleep-related symptoms, the most prevalent were the need to urinate (62.9\%), leg cramps during sleep (37.8\%), frequent tossing and turning in bed (37.1\%), feeling too hot or too cold (33.2\%) and awakening for no particular reason $(29.7 \%)$ (Table 3$)$.

Prevalence and percentage of daytime function [SOS part 4] At wake-up time in the morning, 68 participants (26.2\%) felt low energy, while an equal number felt optimistic. Only $16.9 \%$ napped unintentionally during the day; $47.2 \%$ napped intentionally. Half $(49.8 \%)$ of all nappers felt more alert after a nap. During the day, $16.1 \%$ felt extreme sleepy, $16.9 \%$ intensely fatigued and $27.8 \%$ impaired in their daytime functions (Table 4).

\section{Prevalence and percentage of preliminary sleep diagnoses according to the ICSD}

The most prevalent preliminary sleep diagnosis was chronic insomnia (42.5\%), followed by circadian sleepwake disturbances. Table 5 presents the preliminary sleep diagnoses based on a single assessment interview.

\section{Discussion}

To our knowledge, this is the first study to focus on sleep problems in RTx recipients by using a detailed sleep questionnaire (SOS) and subsequent sleep assessment interview. This study describes the frequency of self-reported sleep disturbances in RTx recipients screened with the Survey of Sleep questionnaire (SOS) and the frequency of presumed sleep diagnoses based on the sleep interview.

As shown in Table 1, of the 688 patients invited to participate, roughly $50 \%(n=325)$ registered poor SQ and DS. Figure 1 shows an increasing proportion of participants in the "poor SQ (PSQI $>5)$ \& and DS (ESS $\geq 6)$ " group. Of these 325, 153 (47.1\%) filled in the SOS and 108 (70.6\%) participated in the assessment interview. In addition, poor SQ was significantly more prevalent in participants compared to non-participants. This would support a hypothesis that, even where no therapeutic benefit can be hoped for, patients are more likely to participate in studies directly relevant to their personal experience.

\section{Prevalence and percentages of sleep problems and sleep habits [SOS part 1]}

The most prevalent sleep problem was difficulty staying asleep, followed by problems falling asleep. Both are characteristic of insomnia [20]. Other characteristics of insomnia common in this group were the extended duration of the sleep problem (61.4\% reported durations greater than 2 years), the severity of the sleep problem (26.9\% called their problems severe), the high prevalence of nightly sleeping pill use (32.9\%), sleep latency of $28 \pm 19.3$ minutes, a high number of awakenings $(2.8 \pm 1.8)$ per night, long sleep latency after awakening (21.9 \pm 16.4 minutes), and high ratios of time in bed to hours of sleep ( $8.3 \pm 1.3$ hours) to hours of sleep $6.4 \pm 1.5$. These results corroborate those of Moul et al. (2002), [30] who reported that $68 \%$ of insomnia patients exhibited long-term sleep problems (more than 1 year), severe sleep problems (81\%), high nightly use of sleeping pills (89\%), long sleep latency (53.3 $\pm 51.8 \mathrm{mi}-$ nutes), high numbers of awakenings $(2.7 \pm 1.7)$ per night, long sleep latency after awakening (56.0 \pm 64.7 minutes), and high ratios of time in bed to hours of sleep (8.2 \pm 1.9 hours in bed: $5 \pm 1.7$ hours of sleep). The average sleep duration of $6.4 \pm 1.5$ is very low, as studies have shown that chronic restriction of sleep to $6 \mathrm{~h}$ or less per night produces cognitive performance deficits equivalent to up to 2 nights of total sleep deprivation [31]. Sleep deficits seriously impair waking neurobehavioral functions (lapses in behavioral alertness) in healthy adults [31].

\section{Prevalence and percentages of sleep habits [SOS part 2]}

One third of participants $(n=82)$ reported using sleeping pills; however, the medical chart data showed that very few $(n=9)$ had informed their nephrologists regarding their sleep problems or use of sleep medication. During their post-transplant hospitalization, all RTx recipients receive education regarding over-the-counter medication and medication prescriptions from other physicians, during which they are advised always to consult their nephrologist about possible interactions with their immunosuppressive drugs [32]. This discrepancy may indicate that patients are reluctant to bring up sleep problems, that they do not see sleep disorders as a topic that nephrologists can deal with, or that the nephrologists themselves simply consider sleep disorders a normal side effect of RTx immunosuppressive regimens. Compared to the general population, our prevalence of $32.9 \%$ self-reported sleep medication use is very plausible: sleep medications are used regularly by $3.2 \%$ of subjects 44 or younger, $13.3 \%$ of subjects between 45 and $64,22 \%$ of those between 65 and 74 and $32 \%$ of individuals 75 or older [33].

Prevalence and percentage of sleep symptoms [SOS part 3] The most prevalent night-time symptom was nocturia. The frequency of its occurrence is key to further diagnosis. 
Table 2 General description of the sleep problem [SOS part 1 (overview) \& 2 (sleep habits)]

General sleep problem

Frequency

179

Percentage

69.1

\section{Main sleep problem}

Difficulty falling asleep

Difficulty staying asleep

Awakening early and being unable to fall back asleep

Excessive long sleep at night

Unusual behavior or experiences during sleep (e.g., nightmares, sleepwalking)

Excessive sleepiness during waking hours

Other problems

\section{Judgment of the sleep problem}

Intense severity of the sleep problem (or problems)

Intense amount of interference with ability to function at home, at work, and with other people

Fairly intense sleepiness before bedtime

Better sleep outside compared to the sleep at home

Having regular sleep times

Times related to sleep

Bedtime during the week

Bedtime at weekends

Time of lights off during the week

Sleep latency

Frequencies of sleep interruptions

Sleep latency after interruptions

Wakeup time during the week

Sleep duration

Get up time during the week

Get up time at weekends

How long having sleep problem

Between 6 months and 2 years

Between 2 and 5 years

$>5$ years

\section{Course of the problem}

Becoming worse

Same

Improving

Irregular

Recurring regularly

\section{Frequency}

Every day/night

Sometimes in a week

Sometimes in a month

$\begin{array}{ll}83 & 32.1 \\ 128 & 49.4 \\ 76 & 29.3 \\ 21 & 8.1 \\ 30 & 11.6 \\ 66 & 25.5 \\ 34 & 13.1\end{array}$

67

26.9

48

19.3

127

51.0

11 
Table 3 The 32 most prevalent sleep disturbances out of 45 [SOS part 3 (sleep disturbances)]

\begin{tabular}{|c|c|c|}
\hline Sleep Disturbance of $\mathrm{N}=\mathbf{2 4 9}$ & Frequency & Percentage \\
\hline Need to urinate & 163 & 62.9 \\
\hline Leg cramps during sleep & 98 & 37.8 \\
\hline Frequent tossing and turning & 96 & 37.1 \\
\hline Feeling too hot or too cold & 86 & 33.2 \\
\hline Awaken for no particular reason (spontaneous awakenings) & 77 & 29.7 \\
\hline Feeling anxious or emotionally tense, or worrying about things at bedtime & 72 & 27.8 \\
\hline Physical nervousness and agitation in the evening or at night & 68 & 26.2 \\
\hline Restless, uncomfortable, or "crawling" sensation in your legs during the evening or at night & 62 & 23.9 \\
\hline Awakened by dreams (not nightmares) & 56 & 21.6 \\
\hline Snoring & 54 & 20.8 \\
\hline Feeling physically tense at bedtime & 42 & 16.2 \\
\hline Awakening because of noise or light & 38 & 14.7 \\
\hline Jerking or twitching in feet, legs, or arms during sleep & 34 & 13.1 \\
\hline Large body jerks as you are falling asleep & 33 & 12.7 \\
\hline Awakened by noises & 32 & 12.4 \\
\hline Awakened by recurring dreams & 31 & 12.0 \\
\hline Other pain during sleep & 31 & 12.0 \\
\hline Muscle aches during or after sleep & 30 & 11.6 \\
\hline Grinding teeth & 26 & 10.0 \\
\hline Nightmares & 26 & 10.0 \\
\hline Heartburns or other burning in chest, stomach & 24 & 9.3 \\
\hline Headaches beginning during sleep & 24 & 9.3 \\
\hline Palpitations, heart racing, or irregular heart beat & 23 & 8.9 \\
\hline Other sleep disturbances & 22 & 8.5 \\
\hline Talking in your sleep & 19 & 7.3 \\
\hline Hallucinations as you are falling asleep or waking up, i.e., seeing or hearing things which turn out not to actually be real & 15 & 5.8 \\
\hline Frequent cough & 15 & 5.8 \\
\hline Episodes of confusion during sleep or upon awakening & 14 & 5.4 \\
\hline Awakening choking, smothering, or gasping for air & 13 & 5.0 \\
\hline Periods of not breathing during sleep & 13 & 5.0 \\
\hline Difficulty breathing (including wheezing) & 11 & 4.3 \\
\hline Difficulty swallowing & 11 & 4.2 \\
\hline
\end{tabular}

Nocturnal polyuria (nocturnal urine overproduction) and diminished nocturnal bladder capacity [34] require further testing to exclude urinary tract infections and prostate hyperplasia [35]. Also very prevalent were leg cramps and frequent turning in bed, indicating muscle fatigue, nerve dysfunction or electrolytic imbalances [36]. However, these symptoms could also be indices of restless leg syndrome, periodic limb movements, myositis, or peripheral neuropathy [36]. Similarly, turning or rocking in bed could indicate parasomnia (undesirable physical or behavioral phenomena occurring during the sleep period) [37]. For the diagnosis of parasomnias a careful physical examination is crucial and often a polysomnogram, including an expanded electroencephalographic montage, is necessary to distinguish between parasomnias (non-REM or REM) and nocturnal seizures [37].

Leg cramps during sleep were the second most prevalent sleep symptom (37.8\%), followed by frequent tossing and turning in bed (37.1\%). These two symptoms could be related to restless leg syndrome and/or periodic limb movements. The prevalence of restless leg syndrome in $\mathrm{RTx}$ recipients overall is $4.5 \%$ [38]. For periodic limb movements the overall prevalence is unknown, although there is an improvement from pre- to post-Tx [39]. Nocturnal leg cramps are often associated with vascular disease, lumbar canal stenosis, cirrhosis and hemodialysis 
Table 4 Description of daytime function [SOS part 4 (daytime function)]

\begin{tabular}{|c|c|c|}
\hline & Frequency & Percentage \\
\hline \multicolumn{3}{|l|}{ Typical feelings at awakening in the morning } \\
\hline Optimistic & 68 & 26.2 \\
\hline Low energy & 68 & 26.2 \\
\hline Energetic & 44 & 17.0 \\
\hline Refreshed & 28 & 10.8 \\
\hline Irritable & 18 & 6.9 \\
\hline Other & 17 & 6.6 \\
\hline Depressed & 16 & 6.2 \\
\hline Anxious & 14 & 5.4 \\
\hline Confused & 4 & 1.5 \\
\hline \multicolumn{3}{|l|}{ Nap behavior } \\
\hline Intentional napping & 118 & 47.4 \\
\hline Unintentional napping & 42 & 16.9 \\
\hline Falling 1-2 times a day asleep or nap during the day & 62 & 24.9 \\
\hline Often dreaming when falling asleep or nap during the day & 10 & 3.9 \\
\hline Feeling more alert and awake after falling asleep or nap & 124 & 49.8 \\
\hline \multicolumn{3}{|l|}{ Daytime function } \\
\hline Extreme amount of sleepiness during daytime & 40 & 16.1 \\
\hline Had an accident because of sleepiness or falling asleep & 11 & 4.4 \\
\hline Intense amount of fatigue during the day & 42 & 16.9 \\
\hline Have to close eyes during the day to relax & 78 & 31.3 \\
\hline Impaired daytime functioning because of nighttime sleep disturbances, daytime sleepiness or fatigue & 72 & 27.8 \\
\hline \multicolumn{3}{|l|}{ Best function during the day } \\
\hline Early morning & 102 & 39.4 \\
\hline Late morning & 83 & 32.0 \\
\hline Early afternoon & 38 & 14.7 \\
\hline Late afternoon & 41 & 15.8 \\
\hline Early evening & 34 & 13.1 \\
\hline Late evening & 18 & 6.9 \\
\hline During the night & 4 & 1.5 \\
\hline No specific time & 35 & 13.5 \\
\hline
\end{tabular}

[36], however no prevalence is known for RTx recipients. The sensorimotor symptoms of restless leg syndrome and/or periodic limb movements can be treated with dopamine agonists, gabapentin and its derivatives, and opioids [40]. To summarize, in-depth assessment of all these listed symptoms is crucial for the right treatment choice.

Prevalence and percentage of daytime function [SOS part 4] Table 4 shows the high prevalence of daytime sleepiness, tiredness and impaired daytime functioning, highlighting the importance for affected patients to use reminders (e.g., pillbox alarms, SMS reminder functions, or other cues) to ensure punctual intake of their immunosuppressive drugs. An earlier study showed correlations between DS and impaired immunosuppressive medication adherence [Burkhalter $\mathrm{H}$, Wirz-Justice A, Cajochen C, Weaver T, Steiger J, Fehr T, Venzin R, De Geest $\mathrm{S}$ : Daytime sleepiness is associated with immunosuppressive non-adherence in renal transplant recipients: a cross-sectional multi-center study. Submitted]. However, it is possible that compensating behaviors such as increased use of mild stimulants (e.g., caffeine, nicotine) (Table 1) account for the lower prevalence of non-adherence (16\%) than of DS (52\%) [41].

Napping behavior and sleep duration depends on cultural, environmental, occupational and health factors [42]. In this study, $47.4 \%$ of participants reported intentional 
Table 5 Frequency of preliminary sleep diagnosis based on the interview grouped into the international classification of sleep disorders categories

\begin{tabular}{|c|c|c|}
\hline $\mathrm{N}=164$ & Frequency & Percentage \\
\hline \multicolumn{3}{|l|}{ Insomnias } \\
\hline Psychophysiological insomnia or paradoxical insomnia & 53 & 32.3 \\
\hline Adjustment insomnia & 3 & 1.8 \\
\hline Inadequate sleep hygiene & 5 & 3.0 \\
\hline Insomnia due to medical condition & 9 & 5.5 \\
\hline \multicolumn{3}{|l|}{ Sleep Related Breathing Disorders } \\
\hline Obstructive Sleep Apnea, Adult & 8 & 4.9 \\
\hline Other Sleep Related Breathing Disorders & 5 & 3.0 \\
\hline \multicolumn{3}{|c|}{$\begin{array}{l}\text { Hypersomnias of Central Origin Not Due to a Circadian Rhythm Sleep Disorder, Sleep Related Breathing Disorder or } \\
\text { Other Cause of Disturbed Nocturnal Sleep }\end{array}$} \\
\hline Behaviorally induced insufficient sleep syndrome & 11 & 6.7 \\
\hline Idiopathic hypersomnia with long sleep time & 7 & 4.3 \\
\hline Hypersomnia due to drug or substance use & 1 & 0.6 \\
\hline \multicolumn{3}{|l|}{ Circadian Rhythm Sleep Disorders (CRSD) } \\
\hline CRSD delayed sleep phase type & 22 & 13.4 \\
\hline CRSD advanced sleep phase type & 3 & 1.8 \\
\hline CRSD irregular Sleep-Wake Type & 8 & 4.9 \\
\hline \multicolumn{3}{|l|}{ Parasomnias } \\
\hline Nightmare Disorder & 4 & 2.4 \\
\hline Parasomnia due to drug or substances & 4 & 2.4 \\
\hline Confusional Arousals & 4 & 2.4 \\
\hline Parasomnia due to med conditions & 2 & 1.2 \\
\hline Sleep Related Movement Disorders & 1 & 0.6 \\
\hline Isolated Symptoms, Apparent Normal Variants, and Unresolved Issues & 0 & 0.0 \\
\hline Other Sleep Disorders & 0 & 0.0 \\
\hline No presumed diagnosis & 14 & 8.5 \\
\hline
\end{tabular}

napping, a behavior shown to be protective against mortality [42]. However, a nap lasting several hours [43] might interfere with nighttime sleep-a point which would have to be borne in mind while counseling patients regarding sleep hygiene. The ideal nap duration for adults is about 10-20 minutes and the timing depends on the quality of sleep duration the preceding night, amount of prior wakefulness and morningness-eveningness tendencies [44].

Prevalence and percentages of preliminary sleep diagnoses This study's most prevalent sleep diagnosis was chronic insomnia, followed by circadian rhythm sleep disorders. The prevalence of insomnia in the general population is $15-20 \%$ [45] and prevalence of circadian rhythm sleep disorders ranges from $3.1 \%$ in adults aged $40-64$ to $16 \%$ in adolescents [46]. Our prevalence of $42.6 \%$ insomnia and $20.1 \%$ CRSD is only partially comparable based on our group's pre-selection criteria (RTx recipients having poor SQ and/or DS). Various publications suggest RTx recipients' sleep disorders are related to medications (e.g., $\beta$-blockers [47], nonsteroidal anti-inflammatory drugs [48], corticosteroids [49] and mycophenolic acid [50]) and other clinical conditions [51,52]. Molnar et al. [53] list numerous potential causes of sleep disorders in this group, including pre-existing sleep disorders, transplant surgery, hospitalization, anxiety and uncertainty, fear of organ rejection, immunosuppressive medication, deteriorating kidney function and co-morbid medical conditions, psychosocial problems, psychiatric and neurological disturbances, lifestyle, diet, environmental factors and aging. With so many possible contributing factors, the most appropriate course of action might be a referral to a sleep expert, who could counsel the patient on the full range of behavioral and medical interventions available, and help them to choose those best suited to their needs [54]. Sleep interventions for RTx recipients are the same as for the general population, apart from the risk of interaction with immunosuppressive therapy and the need to consider the long-term side effects of their therapy (e.g., osteoporosis, new onset of diabetes, pain). 


\section{Limitation of this study}

Since only 249 RTx recipients filled in the questionnaire, of which only 164 (65.9\%) gave interviews, the generalizability of this study's findings are limited. In addition, the high prevalence of RTx recipients in the "poor SQ (PSQI $>5$ ) \& and excessive DS (ESS $\geq 6$ )" group showing an increasing proportion along the study steps, limits the significance and comparability of the presumed sleep diagnoses.

\section{Suggested further research}

Further research will be necessary to develop safe interventions for RTx recipients with sleep-wake disturbances, taking into account their impaired renal function (limited organ survival), high risk of skin cancer (a side-effect of immunosuppressive treatment) and need to adhere to their medication regimens (high risk of acute graft rejection). These interventions should include education [55] regarding sleep disorders and their negative health impacts. Apart from established cognitive and behavioral interventions for insomnia, new chronotherapeutics treatments, particularly bright light therapy and melatonin supplementation [56] should be investigated. For RTx recipients, who already have a high number of medications to ingest daily, light therapy might be a realistic intervention to stabilize sleep-wake rhythms compared to melatonin supplementation (one more drug to ingest).

\section{Conclusion}

Our findings show high prevalence of insomnia and of impaired daytime functionality. This indicates a need for further research on the clinical consequences of sleepwake disturbances and the benefits of insomnia treatment in RTx recipients.

\section{Abbreviations \\ CRSD: Circadian Rhythm Sleep Disorders; DS: Daytime sleepiness: ESS: Epworth Sleepiness Scale; ICSD: International Classification of Sleep Disorders; PSQI: Pittsburgh Sleep Quality Index; RTx: Renal transplant; SOS: Survey of sleep; SQ: Sleep quality.}

\section{Competing interests}

The results presented in this paper have not been published previously. This study was funded by a research grant from the Swiss Renal Foundation (the Alfred and Erika Bär-Spycher Foundation). There are no conflicts of interest.

\section{Authors' contributions}

HB conceived this study with SDG, DPB, AWJ, JS, TF, RMV and TW. HB also coordinated the data collection with the three centers, and collected the data with the centers' physicians, JS, TF and RMV. HB performed the sleep assessments with the expert guidance of DPB. HB, DPB and SDG drafted the article and all authors read and approved the final manuscript.

\section{Acknowledgement}

We gratefully acknowledge all of the volunteers and the ambulatory care teams of the University Hospitals of Basel, Bern and Zürich for their excellent collaboration. Further, we would also like to cordially thank C. Shultis for medical editing.
Collaborating Centers:

Division of Transplant Immunology and Nephrology, University Hospital Basel, Basel, Switzerland

Division of Nephrology, University Hospital Zürich, Zürich, Switzerland

Division of Nephrology, University Hospital Bern' Bern, Switzerland

\section{Author details}

${ }^{1}$ Institute of Nursing Science, University of Basel, Basel, Switzerland. ${ }^{2}$ Centre for Sleep Medicine Hirslanden, Zürich, Switzerland. ${ }^{3}$ Centre for Chronobiology, Psychiatric Clinics, University of Basel, Basel, Switzerland. ${ }^{4}$ Department of Biobehavioral and Health Sciences, University of Illinois Chicago College of Nursing, Chicago, USA. ${ }^{5}$ Division of Transplant Immunology and Nephrology, University Hospital Basel, Basel, Switzerland. ${ }^{6}$ Division of Nephrology, University Hospital Zürich, Zürich, Switzerland. ${ }^{7}$ Division of Nephrology, University Hospital Bern, Bern, Switzerland. ${ }^{8}$ Center for Health Services and Nursing Research, KU Leuven, Belgium.

Received: 3 June 2013 Accepted: 9 October 2013

Published: 10 October 2013

\section{References}

1. Eryilmaz MM, Ozdemir C, Yurtman F, Cilli A, Karaman T: Quality of sleep and quality of life in renal transplantation patients. Transplant Proc 2005 37(5):2072-2076.

2. Kachuee H, Ameli J, Taheri S, Assari S, Riahipour F, Khedmat H, Saadat AR: Sleep quality and its correlates in renal transplant patients. Transplant Proc 2007, 39(4):1095-1097.

3. Sabbatini M, Crispo A, Pisani A, Gallo R, Cianciaruso B, Fuiano G, Federico S, Andreucci VE: Sleep quality in renal transplant patients: a never investigated problem. Nephrol Dial Transplant 2005, 20(1):194-198.

4. Burkhalter H, Sereika SM, Engberg S, Wirz-Justice A, Steiger J, De Geest S: Validity of 2 sleep quality items to be used in a large cohort study of kidney transplant recipients. Prog Transplant 2011, 21(1):27-35.

5. Krystal AD, Edinger JD: Measuring sleep quality. Sleep medicine 2008, 9(Suppl 1):S10-S17.

6. Young TB: Epidemiology of daytime sleepiness: definitions, symptomatology, and prevalence. J Clin Psychiatry 2004, 65(Suppl 16):12-16.

7. Burkhalter H, Sereika SM, Engberg S, Wirz-Justice A, Steiger J, De Geest S: Sleep quality description based on the Pittsburgh Sleep Quality Index in renal transplant recipients. In Organ Transplantation: Ethical, Legal and Psychosocial Aspects Expanding the European Platform. Volume 2, edn. Edited by Weimar W, Bos MA, Busschbach JJ. Lengerich/Germany: PABST Science Publishers; 2011.

8. Burkhalter H, Wirz-Justice A, Cajochen C, Weaver T, Steiger J, Fehr T, Venzin $R$, De Geest S: Validation of a single item to assess daytime sleepiness for the Swiss Transplant Cohort Study. Prog Transplant 2013, 23(3):220-228.

9. Elder SJ, Pisoni RL, Akizawa T, Fissell R, Andreucci VE, Fukuhara S, Kurokawa K, Rayner HC, Furniss AL, Port FK, et al: Sleep quality predicts quality of life and mortality risk in haemodialysis patients: results from the Dialysis Outcomes and Practice Patterns Study (DOPPS). Nephrol Dial Transplant 2008, 23(3):998-1004.

10. Kumar B, Tilea A, Gillespie BW, Zhang X, Kiser M, Eisele G, Finkelstein F Kotanko P, Levin N, Rajagopalan S, et al: Significance of self-reported sleep quality (SQ) in chronic kidney disease (CKD): the Renal Research Institute (RRI)-CKD study. Clin Nephrol 2010, 73(2):104-114.

11. Rodrigue JR, Mandelbrot DA, Hanto DW, Johnson SR, Karp SJ, Pavlakis M: A cross-sectional study of fatigue and sleep quality before and after kidney transplantation. Clin Transplant 2011, 25(1):E13-E21.

12. Novak M, Molnar MZ, Ambrus C, Kovacs AZ, Koczy A, Remport A, Szeifert L, Szentkiralyi A, Shapiro CM, Kopp MS, et al: Chronic insomnia in kidney transplant recipients. Am J Kidney Dis 2006, 47(4):655-665.

13. Kovacs AZ, Molnar MZ, Szeifert L, Ambrus C, Molnar-Varga M, Szentkiralyi A, Mucsi I, Novak M: Sleep disorders, depressive symptoms and healthrelated quality of life-a cross-sectional comparison between kidney transplant recipients and waitlisted patients on maintenance dialysis. Nephrol Dial Transplant 2011, 26(3):1058-1065.

14. Silva DS, Andrade Edos S, Elias RM, David-Neto E, Nahas WC Castro MC. The perception of sleep quality in kidney transplant patients during the first year of transplantation. Clinics 2012, 67(12):1365-1371.

15. Molnar MZ, Novak M, Szeifert L, Ambrus C, Keszei A, Koczy A, Lindner A, Barotfi S, Szentkiralyi $A$, Remport $A$, et al: Restless legs syndrome, insomnia, and quality of life after renal transplantation. J Psychosom Res 2007, 63(6):591-597. 
16. Reimer J, Franke GH, Lutkes P, Kohnle M, Gerken G, Philipp T, Heemann U: Quality of life in patients before and after kidney transplantation. Psychother Psychosom Med Psychol 2002, 52(1):16-23.

17. Kosmadakis GC, Medcalf JF: Sleep disorders in dialysis patients. Int J Artif Organs 2008, 31(11):919-927.

18. Hanly P: Sleep disorders and end-stage renal disease. Curr Opin Pulm Med 2008, 14(6):543-550.

19. Hanly PJ, Gabor JY, Chan C, Pierratos A: Daytime sleepiness in patients with CRF: impact of nocturnal hemodialysis. Am J Kidney Dis 2003, 41(2):403-410.

20. American Academy of Sleep Medicine: The International Classification of Sleep Disorders, Diagnostic and Coding Manual, 2 edn. Weschester, Illinois: American Academy of Sleep Medicine, in association with the European Sleep Research Society, Japanese Society of Sleep Research, Latin American Sleep Society; 2005.

21. Douglas NJ, Thomas S, Jan MA: Clinical value of polysomnography. Lancet 1992, 339(8789):347-350.

22. Moul DE, Hall M, Pilkonis PA, Buysse DJ: Self-report measures of insomnia in adults: rationales, choices, and needs. Sleep Med Rev 2004, 8(3):177-198,

23. Buysse DJ, Reynolds CF 3rd, Monk TH, Berman SR, Kupfer DJ: The Pittsburgh Sleep Quality Index: a new instrument for psychiatric practice and research. Psychiatry Res 1989, 28(2):193-213.

24. Riegel B, Moelter ST, Ratcliffe SJ, Pressler SJ, De Geest S, Potashnik S, Fleck D, Sha D, Sayers SL, Weintraub WS, et al: Excessive daytime sleepiness is associated with poor medication adherence in adults with heart failure. J Card Fail 2011, 17(4):340-348.

25. Johns MW: A new method for measuring daytime sleepiness: the Epworth sleepiness scale. Sleep 1991, 14(6):540-545.

26. Charlson ME, Pompei P, Ales KL, MacKenzie CR: A new method of classifying prognostic comorbidity in longitudinal studies: development and validation. J Chron Dis 1987, 40(5):373-383.

27. Buysse DJ, Germain A, Moul DE, Franzen PL, Brar LK, Fletcher ME, Begley A, Houck PR, Mazumdar S, Reynolds CF 3rd, et al: Efficacy of brief behavioral treatment for chronic insomnia in older adults. Arch Intern Med 2011, 171(10):887-895.

28. Germain A, Moul DE, Franzen PL, Miewald JM, Reynolds CF 3rd, Monk TH, Buysse DJ: Effects of a brief behavioral treatment for late-life insomnia: preliminary findings. J Clin Sleep Med 2006, 2(4):403-406

29. Buysse DJ: Diagnosis and assessment of sleep and circadian rhythm disorders. J Psychiatr Pract 2005, 11(2):102-115

30. Moul DE, Nofzinger EA, Pilkonis PA, Houck PR, Miewald JM, Buysse DJ: Symptom reports in severe chronic insomnia. Sleep 2002, 25(5):553-563.

31. Van Dongen HP, Maislin G, Mullington JM, Dinges DF: The cumulative cost of additional wakefulness: dose-response effects on neurobehavioral functions and sleep physiology from chronic sleep restriction and total sleep deprivation. Sleep 2003, 26(2):117-126.

32. Mohammadpour N, Elyasi S, Vahdati N, Mohammadpour AH, Shamsara J: A review on therapeutic drug monitoring of immunosuppressant drugs. Iran J Basic Med Sci 2011, 14(6):485-498.

33. Ohayon MM, Lemoine P: Sleep and insomnia markers in the general population. Encéphale 2004, 30(2):135-140.

34. Lose G, Alling-Moller L, Jennum P: Nocturia in women. Am J Obstet Gynecol 2001, 185(2):514-521

35. Asplund R: Pharmacotherapy for nocturia in the elderly patient. Drugs Aging 2007, 24(4):325-343.

36. Allen RE, Kirby KA: Nocturnal leg cramps. Am Fam Physician 2012 86(4):350-355

37. Wills L, Garcia J: Parasomnias: epidemiology and management. CNS Drugs 2002, 16(12):803-810

38. Molnar MZ, Szentkiralyi A, Lindner A, Czira ME, Szeifert L, Kovacs AZ, Fornadi K, Szabo A, Rosivall L, Mucsi I, et al: Restless legs syndrome and mortality in kidney transplant recipients. Am J Kidney Dis 2007, 50(5):813-820.

39. Beecroft JM, Zaltzman J, Prasad GV, Meliton G, Hanly PJ: Improvement of periodic limb movements following kidney transplantation. Nephron Clinical practice 2008, 109(3):c133-c139.

40. Rye DB, Trotti LM: Restless legs syndrome and periodic leg movements of sleep. Neurol Clin 2012, 30(4):1137-1166.

41. Nehlig A: Is caffeine a cognitive enhancer? J Alzheimers Dis 2010, 20(Suppl 1):S85-S94.

42. Cohen-Mansfield J, Perach R: Sleep duration, nap habits, and mortality in older persons. Sleep 2012, 35(7):1003-1009.
43. Picarsic JL, Glynn NW, Taylor CA, Katula JA, Goldman SE, Studenski SA, Newman AB: Self-reported napping and duration and quality of sleep in the lifestyle interventions and independence for elders - pilot study. J Am Geriatr Soc 2008, 56(9):1674-1680.

44. Milner CE, Cote KA: Benefits of napping in healthy adults: impact of nap length, time of day, age, and experience with napping. J Sleep Res 2009, 18(2):272-281

45. Chan-Chee C, Bayon V, Bloch J, Beck F, Giordanella JP, Leger D: Epidemiology of insomnia in France. Revue d'epidemiologie et de sante publique 2011, 59(6):409-422.

46. Sack RL, Auckley D, Auger RR, Carskadon MA, Wright KP Jr, Vitiello MV, Zhdanova IV: Circadian rhythm sleep disorders: part II, advanced sleep phase disorder, delayed sleep phase disorder, free-running disorder, and irregular sleep-wake rhythm. An American Academy of Sleep Medicine review. Sleep 2007, 30(11):1484-1501.

47. Stoschitzky K, Sakotnik A, Lercher P, Zweiker R, Maier R, Liebmann P, Lindner W: Influence of beta-blockers on melatonin release. Eur J Clin Pharmacol 1999, 55(2):111-115.

48. Murphy PJ, Myers BL, Badia P: Nonsteroidal anti-inflammatory drugs alter body temperature and suppress melatonin in humans. Physiol Behav 1996, 59(1):133-139.

49. Roux FJ, Kryger MH: Medication effects on sleep. Clin Chest Med 2010 31(2):397-405

50. Almeida S, Filipe A, Neves R, Spinola AC, Tanguay M, Ortuno J, Farre A, Torns A: Mycophenolate mofetil 500-mg tablet under fasting conditions: singledose, randomized-sequence, open-label, four-way replicate crossover, bioequivalence study in healthy subjects. Clin Ther 2010, 32(3):556-574.

51. Kugler C, Fischer S, Gottlieb J, Welte T, Simon A, Haverich A, Strueber M: Health-related quality of life in two hundred-eighty lung transplant recipients. J Heart Lung Transplant 2005, 24(12):2262-2268.

52. Molnar-Varga M, Molnar MZ, Szeifert L, Kovacs AZ, Kelemen A, Becze A, Laszlo G, Szentkiralyi A, Czira ME, Mucsi l, et al: Health-related quality of life and clinical outcomes in kidney transplant recipients. Am J Kidney Dis 2011, 58(3):444-452.

53. Molnar MZ, Mucsi I, Novak M: Sleep disorders and qualiy of life in patients after kidney transplantation. In Sleep and quality of life in clinical medicine. edn. Edited by Vester JC. Totowa, NJ: Humana Press; 2008:401-409.

54. Michie S, Richardson M, Johnston M, Abraham C, Francis J, Hardeman W, Eccles MP, Cane J, Wood CE: The Behavior Change Technique Taxonomy (V1) of 93. Building an International Consensus for the Reporting of Behavior Change Interventions. Ann Beh Med: Hierarchically Clustered Techniques; 2013.

55. Troxel WM, Germain A, Buysse DJ: Clinical management of insomnia with brief behavioral treatment (BBTI). Behavioral sleep medicine 2012, 10(4):266-279.

56. Wirz-Justice A, Benedetti F, Terman M: Chronotherapeutics for affective disorders: a clinician's manual for light and wake therapy. Basel: Karger; 2009.

doi:10.1186/1471-2369-14-220

Cite this article as: Burkhalter et al: Self-reported sleep disturbances in renal transplant recipients. BMC Nephrology 2013 14:220

\section{Submit your next manuscript to BioMed Central and take full advantage of:}

- Convenient online submission

- Thorough peer review

- No space constraints or color figure charges

- Immediate publication on acceptance

- Inclusion in PubMed, CAS, Scopus and Google Scholar

- Research which is freely available for redistribution 